\title{
Burrimysis palmeri, a new genus and species of Heteromysini (Crustacea: Mysidacea) from an anchihaline cave lake of Cabrera (Balearic Islands, Mediterranean)
}

\author{
Damià Jaume ${ }^{1}$ \& Lluc García 2 \\ ${ }^{1}$ Departament d'Ecologia, Universitat de Barcelona, Avda. Diagonal, 645, 08028 Barcelona, Spain; \\ ${ }^{2}$ Museu Balear de Ciències Naturals, Ap. 55, 07100 Sóller, Mallorca, Spain
}

Keywords: Mysidacea, Burrimysis, anchihaline waters, Balearic Islands, stygobiont fauna, taxonomy

\begin{abstract}
Burrimysis palmeri, a new genus and species of Heteromysini, is described from the deep layers of an anchihaline cave lake on Cabrera (Balearic Islands). It shares with Mysidetes Holt \& Tattersall and Deltamysis Bowman \& Orsi a third thoracic limb endopodite without enlarged segments, and rudimentary pleopods in adults of both sexes. Nevertheless, Burrimysis differs, among other characters, in the armature and profile of telson and uropods. Its affinities and biogeographic significance remain uncertain.
\end{abstract}

\section{Resumen}

Descripción de Burrimysis palmeri, un nuevo género y especie de mísido Heteromysini, a partir de material colectado en un lago anquihalino de Cabrera (Islas Baleares). El nuevo taxón se caracteriza, junto con los géneros Mysidetes Holt \& Tattersall y Deltamysis Bowman \& Orsi, por no presentar hipertrofia de los artejos del endopodio del tercer apéndice torácico, así como por la ausencia de dimorfismo sexual en los pleópodos, que se mantienen rudimentarios. No obstante, difiere de ambos géneros, entre otros caracteres, por la forma y armadura del telson y urópodos. Sus afinidades filéticas y significado biogeográfico son inciertas.

\section{Introduction}

Twenty-two blind and unpigmented mysids were trapped in the deeper zone (ca. $15 \mathrm{~m}$ ) of an anchihaline cave lake without known direct marine connection on Cabrera, Balearic Islands. Cabrera is the main island of a group of 17 islands, all scarcely
$20 \mathrm{~km}^{2}$ in area. The archipelago is located $7 \mathrm{~km}$ off the south coast of Mallorca.

Based on this material, Burrimysis palmeri is described, a new genus and species of Heteromysini. It is the first blind mysid known from anchihaline habitats in the Mediterranean area. The accompanying fauna consisted of the melitid amphipod Psammogammarus burri (Jaume \& García, 1992a), the cirolanid isopod Metacirolana ponsi (Jaume \& García, 1992b), and Copepoda, including two new misophrioids (Misophrioida n. gen., n. sp. and Speleophria n. sp.) and a yet unidentified harpacticoid (Jaume, in prep.). The material has been deposited for the greater part in the crustacean collection of the "Museu de la Naturalesa de les Illes Balears"' (MNCM) of Palma de Mallorca.

The description below applies to both male and female unless otherwise stated. Generally, setules on feathered setae are not shown in the figures.

\section{Taxonomic part}

HETEROMYSINI Hansen, 1910 emend. Bowman \& Orsi, 1992

\section{Burrimysis n. gen.}

Diagnosis. - Blind mysids with oval antennal scale, setose all around; distal articulation absent. Male lobe of antennule reduced, lacking any sculpture, 
and armed with a group of long setae. Long nail absent on distal segment of endopodite of first thoracic limb. Endopodite of third thoracic limb with carpus and propodus fused and divided in a number of subsegments; endopodite neither stouter than those of other thoracic limbs, nor modified into strong prehensile claw: Pleopods rudimentary and similar in adults of both sexes. Endopodite of uropod with one stout seta inserted near statocyst on inner margin, and row of irregularly spaced short and slender setae along outer margin. Telson cleft. Females with marsupium formed by only one pair of oostegites.

Type species. - Burrimysis palmeri n. sp., by monotypy.

Derivatio nominis. - Named after the typelocality, Cova des Burrí.

Burrimysis palmeri n. sp. (Figs. 1-40)

Material examined. - Cova des Burrí (Cabrera, Balearic islands). Cave entrance at $20 \mathrm{~m}$ above sea level just in front of Ses Bledes islet. In anchihaline lake occupying the bottom of the cave. Collected by Damià Jaume \& Lluc García, 13 Jan. 1991. Holotype: $\sigma$ of $7.1 \mathrm{~mm}$ (registration number: MNCM-132); allotype: $\odot$ of $5.9 \mathrm{~mm}$ (MNCM-131). Paratypes: $1 \&$ of $6.2 \mathrm{~mm}$ and $6 \sigma \sigma$ of $6.8,7.6,6.7,7.2,6.2$ and $5.8 \mathrm{~mm}$ (MNCM-133 to 139). Furthermore, 13 individuals, with thoracic limbs more or less damaged, are deposited in the authors' personal collection.

Description. - Carapace (Figs. 1-3) well developed, covering thorax laterally, but leaving part of seventh and all of eighth thoracic somites dorsally exposed; first abdominal somite not covered by carapace laterally. Frontal margin of carapace slightly produced as short evenly pointed rostral plate covering only basal part of ocular peduncles. Short rostral process present, downcurved. Anterolateral angles blunt, not produced into spines. Posterior margin evenly emarginate, entire and unadorned. Ocular peduncles as long as wide, lacking finger-like processes.

Abdomen (not illustrated) curved evenly downward, 1.4 times as long as thorax, with sixth somite less than twice length of other somites.

Antennule (Figs. 4, 5): Peduncle slightly longer than both exopodite ("scale") and peduncle of antenna. First segment as long as third, bearing middorsal papilla on distal margin with 5 setae, and 2 more stout setae inserted mediolaterally; lateral papilla produced apically into finger-like process bearing 5 setae on tip, 2 of which stouter than others; this process surpasses twice length of lateral margin of second segment. Second segment less than half length of first segment, bearing also middorsal papilla, with 4 setae, on distal margin; 2 setae, longer than those of papilla, inserted on distomedial corner. Third segment with middorsal papilla on distal margin, different in structure from those of first 2 segments: with 4 lateral setae, similar to those of other papillae, but also with transverse lamellae on surface of medial side; 3 setae, longer than those of papilla, inserted on distomedial corner; 2 setae implanted roughly in middle of dorsal surface of segment; male lobe reduced to small setiferous ridge; 1 seta between male lobe and inner distal corner of third segment, inserted very close to male lobe. Outer flagellum $87 \%$ of body length, basal segments not swollen and lacking bristles or sensory hairs; inner flagellum without peculiarities, half as long as outer one. Antennule of female adorned as in male, except for absence of male lobe.

Antenna (Fig. 6): Exopodite ("scale") more than 4 times longer than wide. Antennal peduncle longer than scale, $1 / 3$ of length of outer flagellum of antennule, 3-segmented, second segment longer than third, setation as illustrated.

Labrum (Fig. 7) globular, lacking spines; distal margin asymmetrical, with a microtuberculate sclerotized surface and rounded swelling on right half, and left half covered by small setules.

Mandibular palp (Fig. 8) 3-segmented. First segment small, naked. Second segment elongate with conspicuously swollen central region, bearing row of 16 stout setae on lateral margin, and row of 15 on medial margin; 1 seta implanted on distal corner of medial side. Third segment roughly $1 / 3$ length of second, of rhomboid shape; lateral margin with long seta on proximal half and row of 14 pectinate setae (distal seta largest) and 1 small, terminal seta; medial margin with row of 4 long setae; row of 7 small setae, length less than $1 / 3$ of those on medial margin, inserted mid-dorsally. Right 


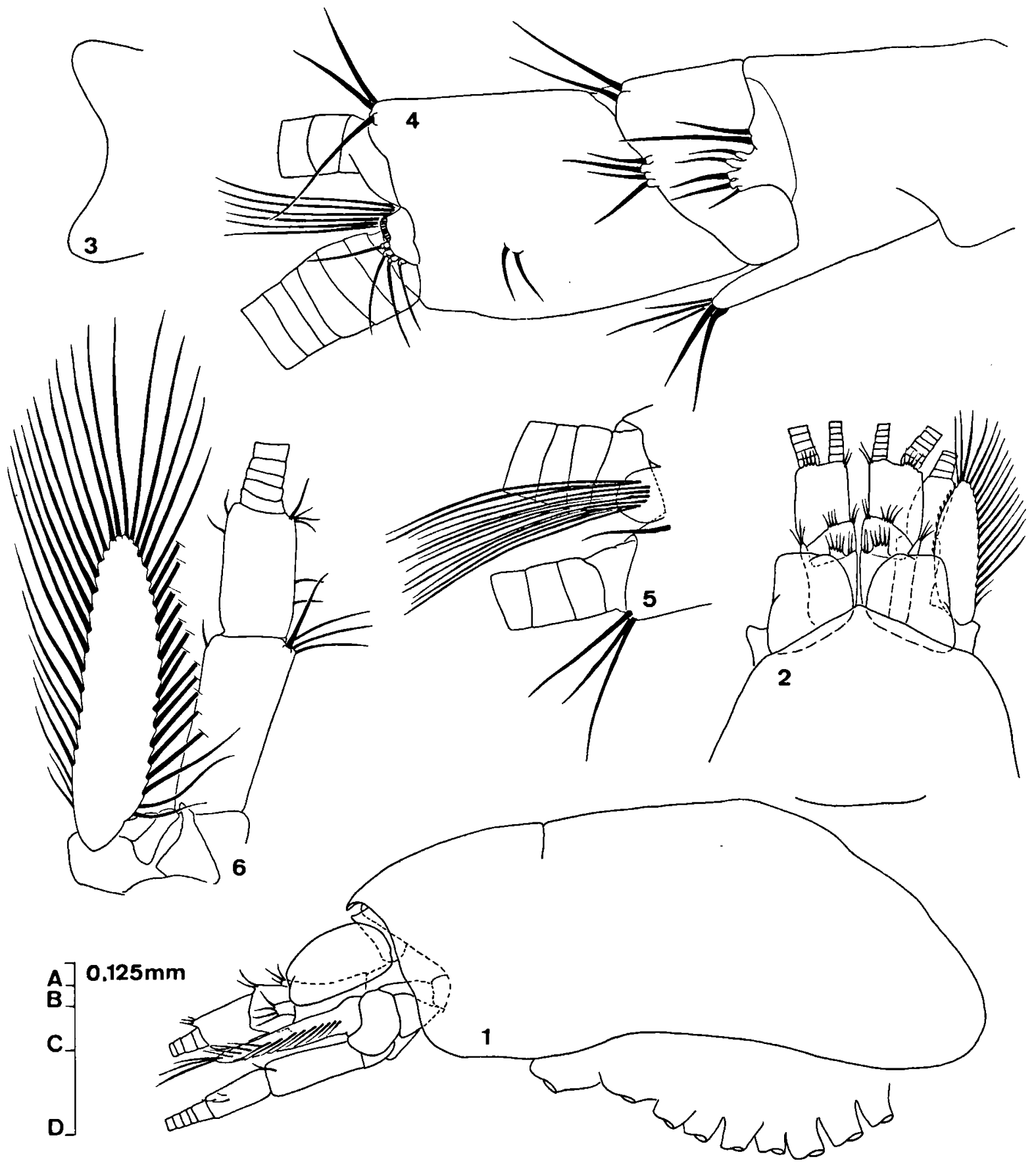

Figs. 1-6. Burrimysis palmeri n. gen., n. sp. (o paratype $7.2 \mathrm{~mm}): 1$, carapace, lateral view (scale B); 2 , dorsal view of frontal zone of carapace (B); 3, dorsal view of distal part of carapace (slightly stretched) (A); 4, antennule peduncle, dorsal view (D); 5, antennule peduncle, ventral view of distal segment (D); 6, peduncle of antenna (C) (flagellum not represented). 


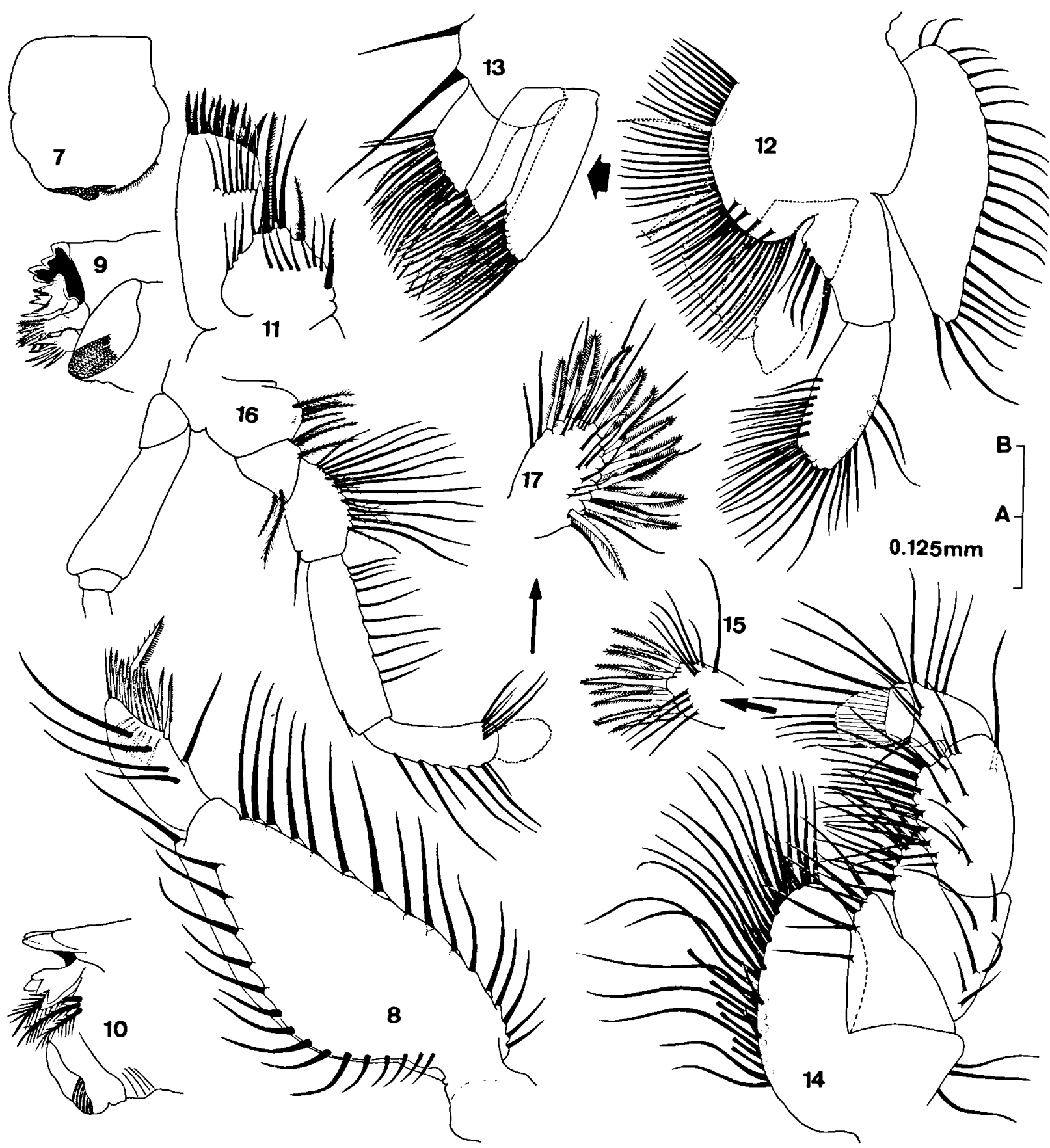

Figs. 7-17. Burrimysis palmeri n. gen., n. sp. ( $\sigma^{\circ}$ paratype $7.2 \mathrm{~mm}$ ): 7, labrum, ventral view (A); 8, mandibular palp (B); 9, right gnathobasic process (B); 10, left gnathobasic process (B); 11, maxillule (B); 12, 13, maxilla (B); 14, 15, first thoracic limb (B); 16 (A), 17 (B), second thoracic limb.

gnathobasic process (Fig. 9): Incisor process 4-dentate; lacinia mobilis as illustrated; 2 stiff setae with fingerlike setose tips between lacinia and pars molaris. Left gnathobasic process (Fig. 10): Incisor process 3-dentate; lacinia mobilis 5-dentate; 3 barbed setae between lacinia and pars molaris. 
Maxillule (Fig. 11): Coxal endite with 3 long stout distal setae (1 pectinate); row of 4 shorter and slender setae on lateral margin, and 2 stout setae, distal one plumose and proximal one denticulate, on medial margin; also row of 7 slender setae at midlength. Basal endite with 11 stout, short denticulate setae on distal margin, and transverse row of 7 setae proximally.

Maxilla (Figs. 12, 13): Exopodite with row of 24 marginal setae. Basal segment of endopodite with 5 setae on proximal half of medial margin; distal segment with up to 31 setae on distal margin and distal half of medial and lateral margins. Coxal endite with 2 long and stout setae, and with lobe bearing up to 19 denticulate setae distally; inner setiferous expansion of basal part present and well developed, bearing up to 41 marginal setae and outer submarginal row of 4 setae. Basal endites with 10 and 16 distal denticulate setae.

First thoracic limb ("maxilliped"; Figs. 14, 15): Endopodite with prominent gnathobasic lobe on inner side of basis, armed marginally with up to 27 setae (6 shorter than others) and 6 tricuspidate spines in proximal half; 3 setae on outer margin of basis. Endite of ischium with 7 setae; merus with 6 setae on outer margin and 10 on inner endite; carpus with 16 setae along inner margin, a group of 9 medial spines, and 1 subterminal seta on outer margin; propodus with 14 setae on distal and 4 on outer margin; dactylus, length equal to propodus, ovoid, bearing 9 barbed spines, one of which slightly more stout, on distal margin, and 2 rows of 4 and 6 setae, implanted subdistally. Exopodite of first limb similar to that of remaining thoracic limbs: a large proximal segment, outer distal angle of which protruded, lacking spines or setation, and flagellum of 8-9 segments, with plumose setae as illustrated in Fig. 28; this pattern is repeated in all thoracic limbs. Size of proximal segment slightly decreasing progressively on posterior thoracic limbs.

Second thoracic limb (Figs. 16, 17): Endopodite similar in form, but more slender and longer than in first limb. Basis with 4 plumose setae on inner margin; no endite developed. Ischium with 3 plumose setae on inner margin and 2 on outer margin; no endite developed. Merus with 11 long, plumose, and 5 shorter, denticulate, setae on inner margin and only 1 subterminal plumose seta on outer margin; no endite developed. Carpus as long as all previous segments combined, bearing 10 plumose setae on inner margin and 1 shorter subterminal seta on outer margin. Propodus slightly shorter than carpus, with 7 plumose setae on outer margin and transverse subterminal row of 6 plumose setae on inner margin. Dactylus ovoid, less than $1 / 3$ of length of propodus, bearing 13 distal barbed spines and up to 27 setae.

Third and fourth thoracic limbs (Figs. 18-23) similar both in size and morphology. Ischium of endopodite shorter than large proximal segment of exopodite and less than half as long as merus; carpopropodus divided into 6 segments, all bearing pectinate terminal seta medioposteriorly. Setation as illustrated.

Fifth to eighth thoracic limbs (Figs. 24-30) similar in morphology, with ischium of endopodite roughly twice as long as large proximal exopodite segment; carpopropodus divided into 5,6 or $7 \mathrm{seg}$ ments, distal one bearing 3-4 conspicuous setae with bulgy basis. Nevertheless, while sixth to eighth endopodites have roughly same length (with ischium roughly twice as long as large proximal segment of exopodite, and merus half as long as ischium) fifth endopodite is longer, being a result of its lengthened merus, slightly shorter than ischium. Setation as illustrated, but note that number of setae in clusters of carpopropodal segments is actually higher than that represented in the figures.

Penis (Figs. 28, 31) subrectangular, shorter than large proximal segment of exopodite of eighth thoracic limb, roughly 3.5 times longer than wide; tip with 1 apical plumose seta and sometimes 2 plumose setae on outer margin. Females with only one pair of oostegites, on the eighth thoracic limbs (Fig. 32), with row of up to 24 setae on outer margin and 4 on distal margin; 2 setae implanted subdistally on inner face.

Pleopods (Figs. 33-37) of mature males as illustrated, not sexually dimorphic, reduced to unsegmented plates, becoming progressively longer on posterior abdominal somites. Apex strongly setose (plumose setae) in all pleopods except first, which bears only 2 apical setae; (4)-5 setae on pseudobranchial lobes. Pleopod 1 apex surpassing slightly pseudobranchial lobe.

Uropods (Figs. 38, 39): Exopodite longer than 


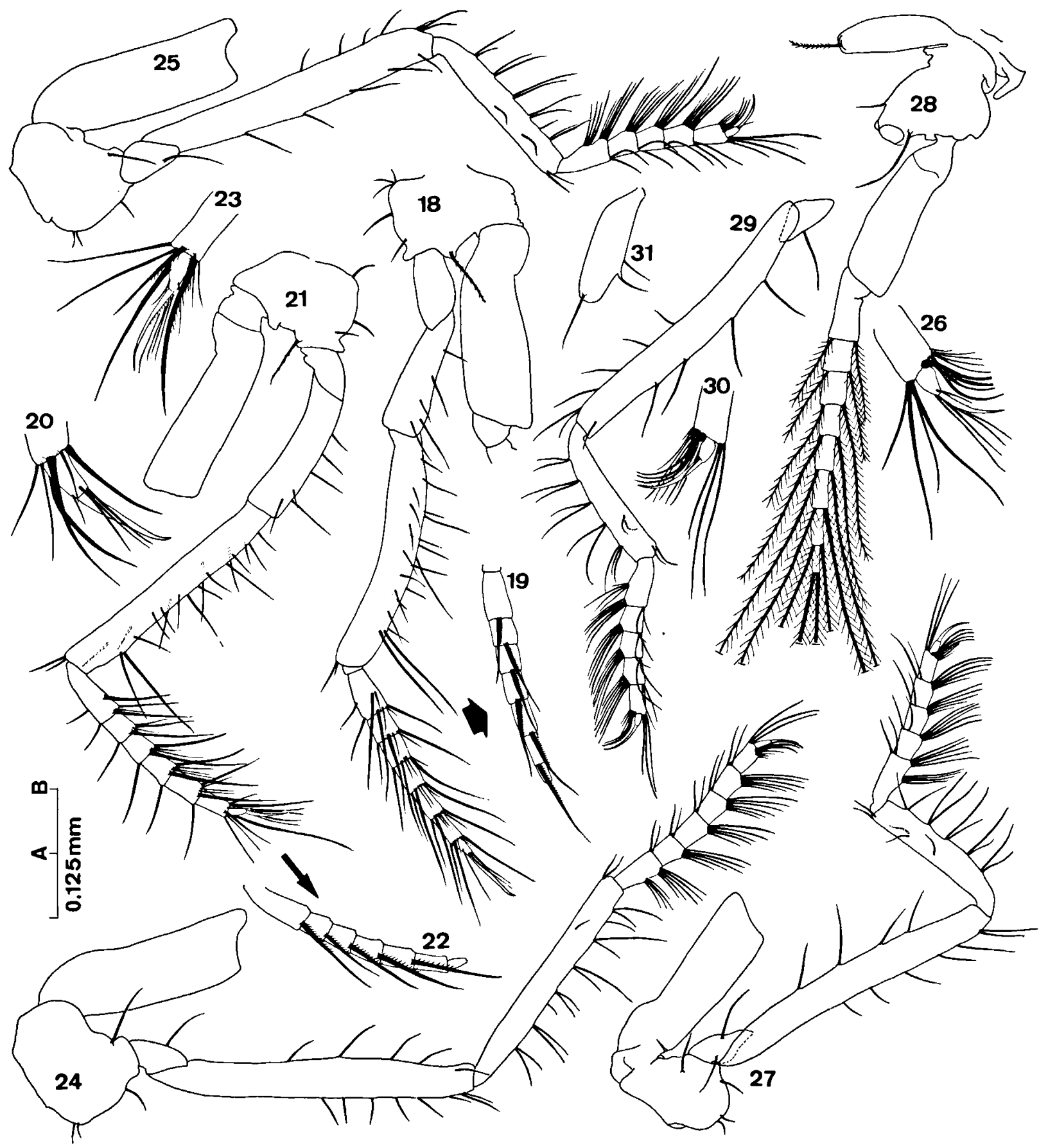

Figs. 18-31. Burrimysis palmeri n. gen., n. sp. (ơ paratype $7.2 \mathrm{~mm}): 18,19$ (A), 20 (B), third thoracic limb; 21,22 (A), 23 (B), fourth thoracic limb; 24, fifth thoracic limb (A); 25 (A), 26 (B), sixth thoracic limb; 27, seventh thoracic limb (A); 28, 29 (A), 30 (B), left eighth thoracic limb; 31, right penis (A).

endopodite, both reaching beyond telson. Exopodite lacking distal suture, setose all around; neither spines nor naked portions present. Endopodite with lateral margin armed with an irregular row of 24 short and slender setae, extending from region of insertion of sympodite to apex; inner margin armed 


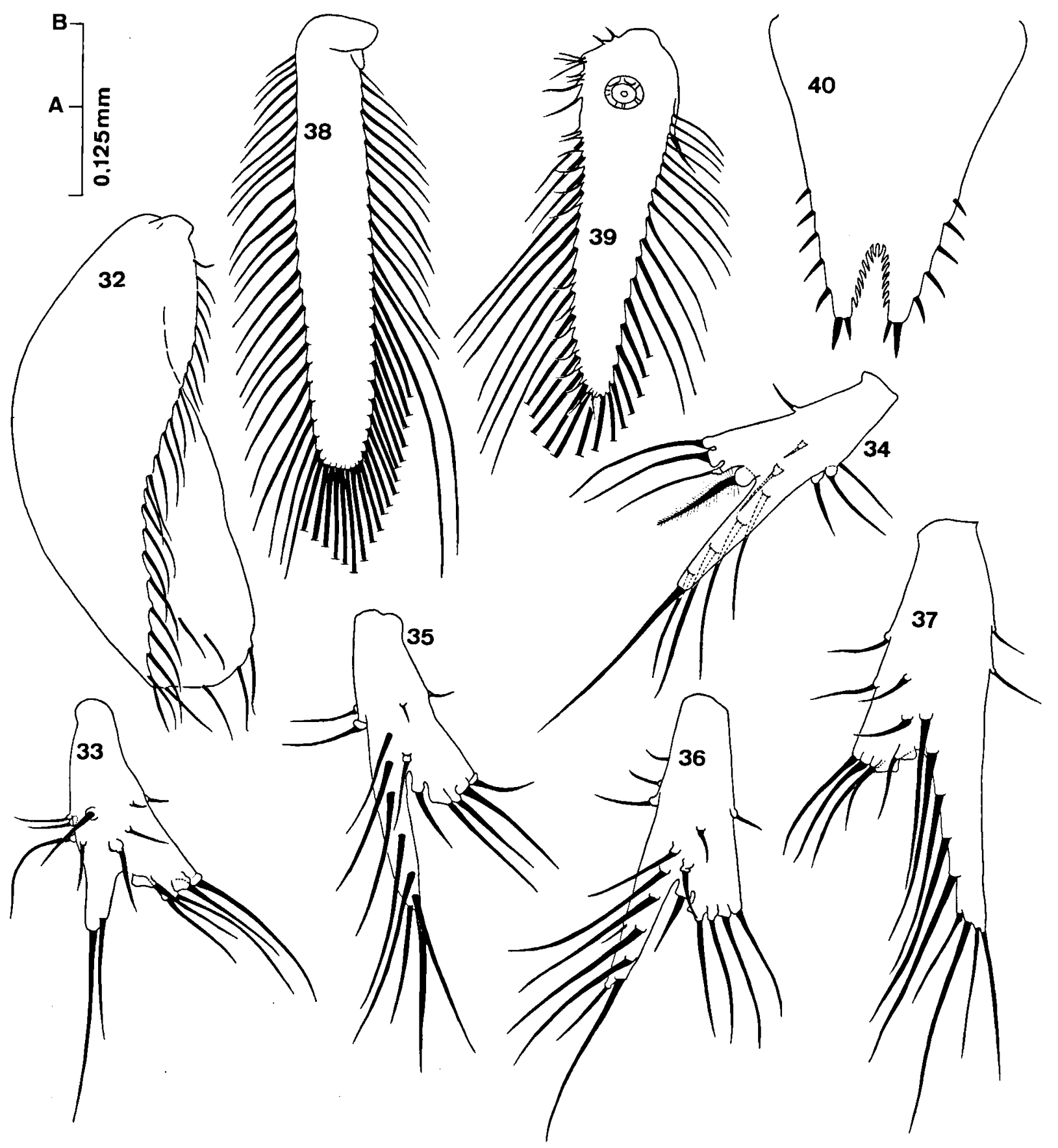

Figs. 32-40. Burrimysis palmeri n. gen., n. sp. (32, ९ paratype $6.2 \mathrm{~mm} ; 33-40$, o paratype $7.2 \mathrm{~mm}): 32$, right oostegite (A); 33, first pleopod (B); 34, second pleopod (B); 35, third pleopod (B); 36, fourth pleopod (B); 37, fifth pleopod (B); 38, exopodite of uropod (A); 39 , endopodite of uropod (A); 40, telson (A). 
with stout seta implanted within short distance of statocyst. Both margins from statocyst to apex without naked portions and fringed with 36 long setae.

Telson (Fig. 40): 1.2 times as long as wide, trapezoidal, width at apex less than $1 / 4$ of basal width. Apex cleft to a depth of 1/4 of telson length, forming an acute angle with distal lobes of telson and armed with 14 stout denticles. Proximal half of margins naked, but the distal half bears 5 wellseparated stout setae on either side; apical lobes each armed with 2 stout setae, outer roughly twice as long as inner one.

Derivatio nominis. - The species is dedicated to Miquel Palmer, who helped us during the fieldwork.

\section{Discussion}

The ascription of Burrimysis to the Heteromysini Hansen, 1910 is here adopted following the emended diagnosis of the tribe presented by Bowman \& Orsi (1992). The modern definition of the Heteromysini (e.g. Tattersall \& Tattersall, 1951) emphasizes the much stouter, prehensile endopodite of the third thoracic limb, showing an undivided carpopropodus, the similar, rudimentary pleopods in both sexes, the long penes, and the reduced armature and size of the male lobe of the antennule. In order to accommodate some taxa (i.e.: Harmelinella Ledoyer, 1989; Deltamysis Bowman \& Orsi, 1992; and also Mysidetes Holt \& Tattersall, 1905) showing a clear Heteromysini facies, but without the endopodite of the third thoracic limb stouter than the other endopodites, Bowman \& Orsi (loc. cit.) present a conditional terminus in their emended diagnosis of the tribe, i.e.: "Pereopod 2 (= endopodite of third thoracic limb) sometimes enlarged and robust".

Burrimysis shows almost completely the "typical" Heteromysini facies: Antennal scale setose all around, carpus and propodus of endopodite of thoracic limbs 4 to 8 fused and divided in a number of subsegments, all pleopods rudimentary in both sexes, telson cleft, cleft armed with teeth, male lobe reduced, etc. The only character state which could impede this assignment would be the ambulatory nature of the endopodite of the third thoracic limb, showing also a segmented carpopropodus, but in accordance with the recently emended definition of the tribe by Bowman \& Orsi (op. cit.), the inclusion of Burrimysis in the Heteromysini seems beyond doubt.

Within the Heteromysini, Burrimysis shows some phenetic affinity with two taxa characterized by the combination of a third thoracic limb endopodite without enlarged segments, and all pleopods rudimentary in both sexes. These are $M y s i$ detes and Deltamysis. Both genera, in contrast to Burrimysis, have well-developed corneas. Burrimysis differs from Mysidetes by, among other characters, the absence of a row of spines along the medial margin of the endopodite of the uropod, the absence of a distal articulation on the antennal scale, and the absence of a long slender nail on the distal segment of the endopodite of the first thoracic limb. Besides, the Burrimysis female marsupium is formed by only one pair of oostegites, versus 3 pairs in Mysidetes. In contrast to Deltamysis, Burrimysis shows a cleft telson and a uropodal endopodite bearing spines.

The biogeographic significance of Burrimysis is practically impossible to ascertain due to numerous reasons: First, it is so far a monotypic genus; second, its affinity with other possible sister groups is not based on a shared derived state of a complex system comprising many integrated parts, i.e., phenetic resemblances do not imply a close phyletic affinity. Some speculations on the ancient, preMessinian, origin of some of the accompanying taxa of Burrimysis in the cave of Cabrera are given elsewhere (Jaume \& García, 1992a) and could be extrapolated to it. Nothing can be deduced of its degree of morphological troglobitization, which is the same as in all other known stygobiont mysids, viz.: reduction or absence of both eyes and body pigmentation.

\section{Acknowledgments}

We are greatly indebted to Drs. T.E. Bowman (Washington), L. Botosaneanu (Amsterdam), and M. Bacescu (Bucarest) for their 
guidance during the preparation of the manuscript. G. Pons and $\mathrm{M}$. Palmer, as always, helped us during the speleological excursions. This work has been financially supported by the program DGICT PB88-0041.

\section{References}

Bowman, T.E. \& J.J. Orsi, 1992. Deltamysis holmquistae, a new genus and species of Mysidacea from the SacramentoSan Joaquin estuary of California (Mysidae: Mysinae: Heteromysini). Proc. biol. Soc. Wash., 105(4): 733-742.
Jaume, D. \& L. García, 1992a. A new Psammogammarus (Amphipoda: Melitidae) from Cabrera (Balearic Islands). Stygologia, 7(2): 107-115.

Jaume, D. \& L. García, 1992b. A new Metacirolana (Crustacea: Isopoda: Cirolanidae) from an anchihaline cave lake on Cabrera (Balearic Islands). Stygologia, 7(3): 179-186.

Tattersall, W.M. \& O.S. Tattersall, 1951. The British Mysidacea. Ray Society Monograph, 136: 1-460 (Ray Society, London).

Received: 1 April 1992. 